\title{
Methods and tools for environmental technologies risk evaluation: the principal guidelines-a review
}

\author{
A. Kowalska' ${ }^{1}$ - A. Grobelak ${ }^{1}$ M. Kacprzak ${ }^{1} \cdot$ K.-A. Lyng ${ }^{2}$
}

Received: 23 January 2020 / Revised: 28 September 2020 / Accepted: 6 October 2020 / Published online: 19 October 2020

(c) The Author(s) 2020

\begin{abstract}
The commonly used and developing engineering environmental technologies do not remain neutral for an ecosystem. The deepening climate changes are generally considered as the effects of human activities. There is thus no doubt that any human interference in the environment should be comprehensively checked at the beginning for all its positive and negative aspects for the environment as well as society health. There are two different analytical tools useful in environmental management: life cycle assessment (LCA) and risk assessment (RA). The first follows the product from "from birth to the grave" summing the environmental impact at all stages of its "life" including such elements like producing, used electricity, transport and many others. LCA refers to quantification and classification of all effects at all life stages and provides direct and indirect possible environmental interactions. On the other hand, risk assessment focuses on linking stressors and its possibilities and severity. RA tools reveal environmental and human health impacts of strictly separated elements, providing insight as to which emission consists of an important threat. This paper is focused on summarizing two the most used methods and tools for supporting the decision making process in use of environmental engineering technologies. In this paper, the fundamental differences between LCA and RA and benefits from their use has been contained.
\end{abstract}

Keywords ERA $\cdot$ LCA $\cdot$ RA life cycle $\cdot$ Environmental management $\cdot$ Decision making support $\cdot$ Climate change

\section{Introduction}

All anthropologic activities do not remain neutral for ecosystems. The deteriorating condition of the Earth and its climate, for instance, global warming, constitute a visible effect of our irresponsible economic management. The higher production, and hence, higher emission of greenhouse gases as well as other toxic substances contribute on a large scale to climate change (Althor et al. 2016). A human interference in the environment is an unequal, onesided fight in which the ecosystem is defenseless. Moreover, the state of the many elements of surrounding environment

Editorial responsibility: M. Abbaspour.

A. Kowalska

aneta.kowalska@pcz.pl

1 Institute of Environmental Engineering and Biotechnology, Faculty of Infrastructure and Environment, Czestochowa University of Technology, Czestochowa, Poland

2 NORSUS Norwegian Institute for Sustainability Research, Stadion 4, 1671 Kråkerøy, Norway has a toxic effect not only for plants, animals, microbiome but also for human health (Harder et al. 2015a, b; Chen et al. 2015). Without strong and concrete steps in this field, it is more than certain that it will lead to environmental disaster. A strong basis indicating the necessity to protect the environment is included in Fig. 1. Further climate changes may cause extinction of many plant and animal species. It is predicted that about $8 \%$ species will become extinct as an effect of climate change. Thus, it is necessary to do what we can to stop a long-term process of environmental poisoning (Kowalska and Grobelak 2020).

Due to the social concerns, a special attention should be paid to the issue of technologies of engineered products with the possibility of its introduction into a soil or water (Yoshida et al. 2018). The assessment of such technologies could be practically impossible without specific and dedicated tools in order to assess the environmental risks. The creation of such tools enables a comprehensive assessment of the impact of a given product, a given interference on the state of the environment including practically all its ingredients: soil, water and air (Denmark 2011). 


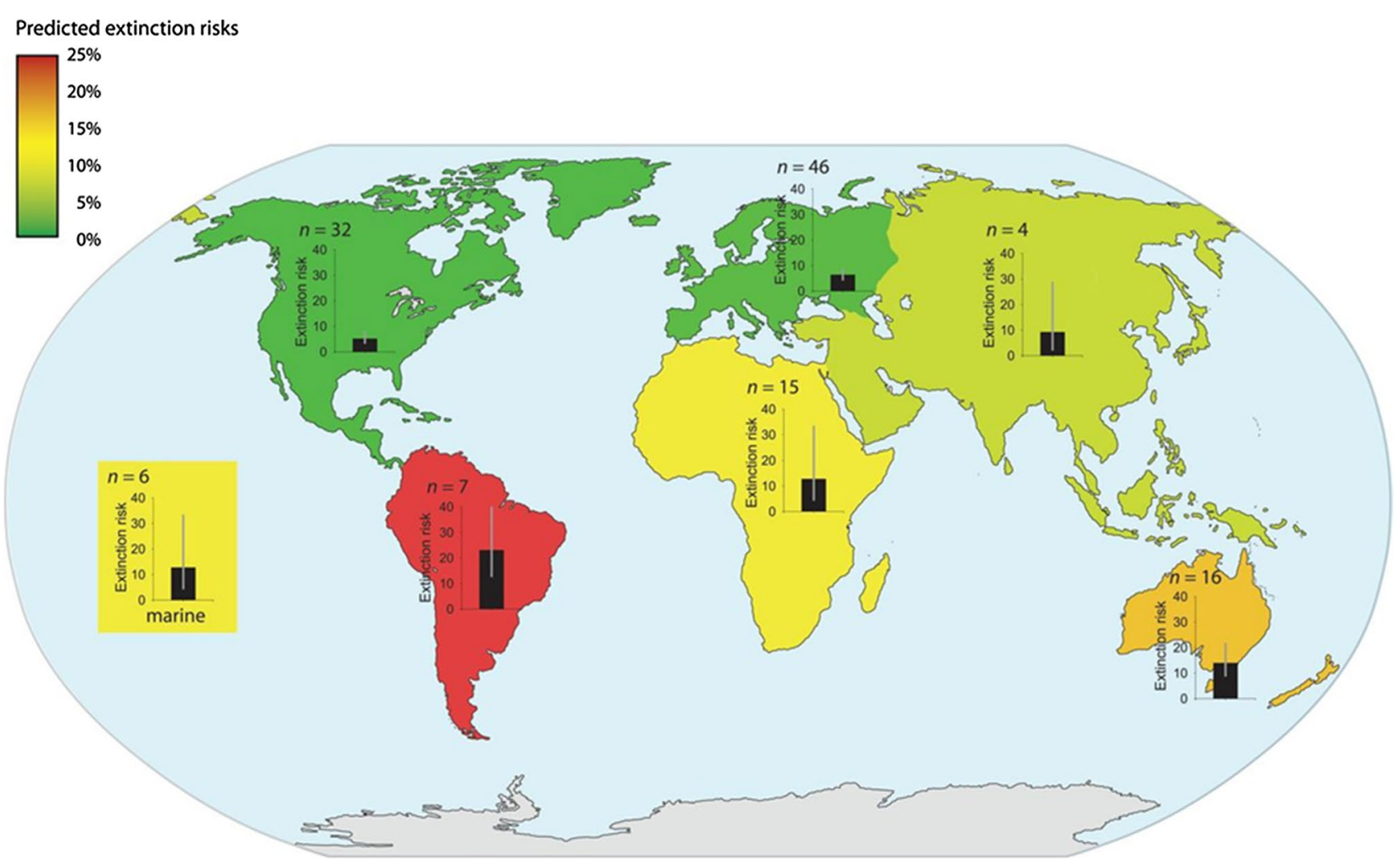

Fig. 1 Predicted extinction risk from climate change differ by region (Urban, 2015)

Environmental risk estimation has to be preceded by meticulous selection of tools that are commercially available on the market and may help prevent limited concerns about environmental issues. Due to the wide range of those tools, the obtained results may be converted to social impact and may consist of a condensed answer to public concerns regarding their health threat. Since life cycle assessment (LCA) and environmental risk assessment (ERA) are suggested as an effective methodologies to holistically assess the potential of different products, this paper reviewed and discussed their separate as well combined application for overall risk estimation.

The process of human interaction with the environment has already been started in neolith, and it expands to new areas gradually with time (Wójcik 2018). Deepening climate changes including global warming, constitute one of the major issues of scientist's concern worldwide (Finnveden et al. 2009). All changes in climate are closely connected with anthropologic activities, development of countries and industrialization and consequently, high emission of greenhouse gases (e.g., carbon dioxide, methane, freons).
However, changes in surrounding environment also consist of effects of a combination of human activity and mainly irrational management. For instance, frequent occurrence of the soil of worse quality and hence shrinking of areas useful for agriculture are due to many overlapping factors: introduction of contaminants into soil, improper fertilization, as well as deposition of pollutants from the air (Różański et al. 2018; Schwarz et al. 2016). Those mentioned factors consist of only a part of all influencing agents on soil quality. Nevertheless, the quality of soil requires close attention because it is an important ingredient of the ecosystem. That is, contaminants included into soil may be transported to the other ecosystem ingredients: to plants, further to animals and humans; to the air; to ground water. Thus, all interference in environment at each stage needs serious rethinking and must be tested for all possible positive as well as negative effects (Grobelak et al. 2017). A similar connection is observed in air and water pollution-all ecosystems interact strongly with each other. In response to the growing attention of scientists and politicians paid on the issue of environmental protection, more and more clean production technologies 
arise. Those technologies refer to the production of human goods with low emission of carbon dioxide and other pollutants (Nan et al. 2019; Suo et al. 2017; Mardones and Bienzobas 2019). Nevertheless, each product needs to be controlled at all stages of its production as well as the influence of its usage on the environment. It is because the overlapping of negative effects intensifies their strength and can have an extremely destructive effect on the environment, which can be seen only after many years.

\section{Environmental risk assessment as a part of sustainable development}

Regarding sustainable development, it is very important for the management of a company to assess environmental impact. By providing the holistic assessment of all possible environmental risks related to the life cycle of given product, there is an opportunity to become a leader in the market. It is so, since a majority of available environmental risk assessments provide clear information about the ecology of a product as well as its costs. Using those tools, a company may choose the best method (in environmental and economy terms) of producing a given product. It is considered that in the future it will be mandatory in the world to receive an environmental risk certificate for all new products entering the market. In the field of environmental protection, the basic cause of environmental problems is inadequate relations between protective measures and development needs. On the one hand, the failure to take into account ecological requirements leads to environmental degradation; on the other hand, the objectives of nature conservation limit the possibility of development of local communities. This apparent conflict results from a misunderstanding of the principles of sustainable development. To help citizens choose environmentally friendly products, the European Union has created an eco-labeling system. Thanks to the eco-management and audit scheme (EMAS), everyone can find out whether the supplier or customer with whom it works follows the high standards in environmental protection. An appropriate environmental supervision program contributes not only to achieving environmental quality, but also provides an economic benefits by gain of the competitive advantage over entities that do not comply with environmental requirements (Torunski 2010). EMAS is considered as an effective instrument at firm level based on improvement of the environmental performance (Montobbio and Solito 2018). It is considered that EMAS strongly supports ecoinnovations and ecological products. The strong advantage of EMAS in environmental point view is that certified companies are obligated to monitor their activities and constantly strive to ameliorate obtained results forcing companies to improve pro-ecological activities. However, EMAS has not been approved by many companies due to the wide range of applications in various industries, so the number of companies covered by this certificate is gradually decreasing (Matuszak-Flejszman et al. 2019).

\section{Analytical methods and tools for risk assessment}

An environmental risk assessment is derived from the analysis of the impact of substances and chemical compounds, their usage and release into the environment. In 1980s, the Environmental Protection Agency created an Integrated Risk Information System (IRIS) (US EPA 1998). The main aim of this base was to provide information about the effect of various substances in the environment on humans (Wójcik 2018). However, it should not be assumed that environmental risk only applies to toxic substances. It can also be applied for example to noise emission. The document Guidelines for Ecological Risk Assessment (Beer and Ziółkowski 1995) divides the risk assessment and risk management as two separate items. At present, the environmental risk assessment is more frequently considered as a strategic operation of enterprises.

Nevertheless, it is important to distinguish two concepts: risk and hazard. Hazard refers to the situation which may lead to damages in certain conditions. In turn, risk refers to the probability of occurrence situation causing the threat as well as the scale of its negative effects (Wójcik 2018). Practically, risk definition has many publications in this field. One of the definitions of risk is as follow: situation or action in which two or more outcomes are possible. There are no concrete effects that may occur, and at least one of them is desirable (Rausand 2011).

One of the most important elements of environmentdependent decision making is a so-called risk-benefits-costs. According to this rule, during assessing a certain action, it is necessary to consider three elements: risks connected with that action, the potential benefits and its economic issue. A good example is the case of remediation of contaminated soil. In the decision making process concerning which methodology should be used, the evaluation of risk of ecological damage due to the contamination, due to remedial action and profitability of remediation (for environment and economy), will be helpful (Suter 2006). 
Health and environmental risk assessment comprises a relatively new field of study. To evaluate the environmental risk, there are available some quite different and commonly used analytical tools useful for environmental management: life cycle assessment, environmental performance evaluation, environmental auditing, risk assessment and environmental impact assessment.

Environmental performance evaluation (EPE) is regulated by ISO norm 14031. EPE consists of a process and tools for management that are designed in order to ensure reliable and verifiable information, useful in the management process. EPE allows determining if an environmental performance in given company meets the criteria set by the management. Using EPE, it is possible to assess an environmental performance against its environmental policy all well as targets and other environmental issues (Jasch 2000).

Environmental risk assessment (ERA) determines the magnitude of risk under environmental changes influencing biological systems. ERA is strongly dependent on substance toxicity and level at which living organisms are exposed (Rosenbaum 2017).

However, the most commonly used analytical tools are: life cycle assessment (LCA) and risk assessment (RA). A history of both tools has an origin in separate groups

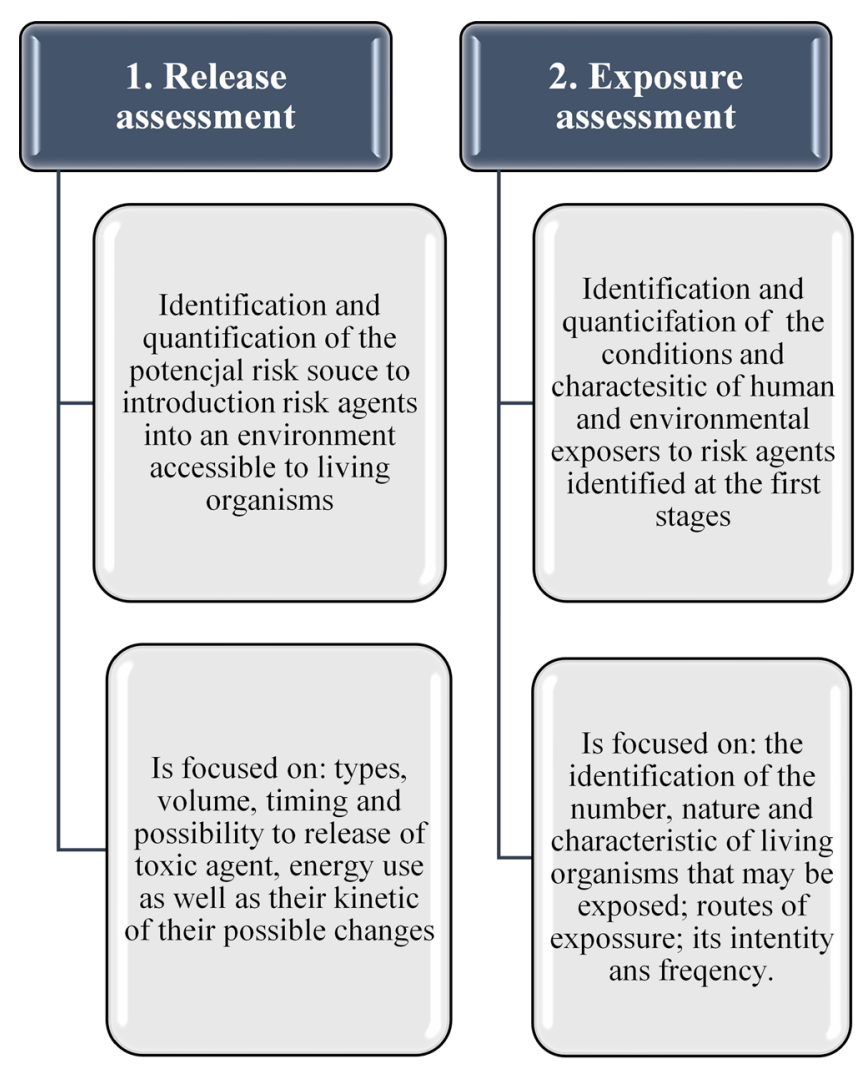

of specialists (Harder et al. 2015a, b). Both of them are described below in detail.

\section{Risk assessment}

Risk assessment constitutes a pro-environmental approach that may reveal the information about the likelihood, severity and consequences of potential ecological threats. The evaluation of risk assessment is based on three main steps: (1) identification of hazard; (2) describing and quantifying risks; and (3) analysis of consequences-comparing and judging the significance of risks (Covello and Merkhofer 1993). It is well known that risk is closely related with its source, the exposure process and the consequence of the process. Thus, risk assessment must be referred to all of the mentioned aspects (Covello and Merkhofer 1993). A well-carried-out risk assessment must contain all stages as follow: release assessment, consequence assessment, exposure assessment and finally-estimation of risk. A brief explanation of those stages is presented in Fig. 2.

Thus, risk assessment refers to the specific material in specific release scenarios. The complete risk assessment comprises risk information and provides valuable

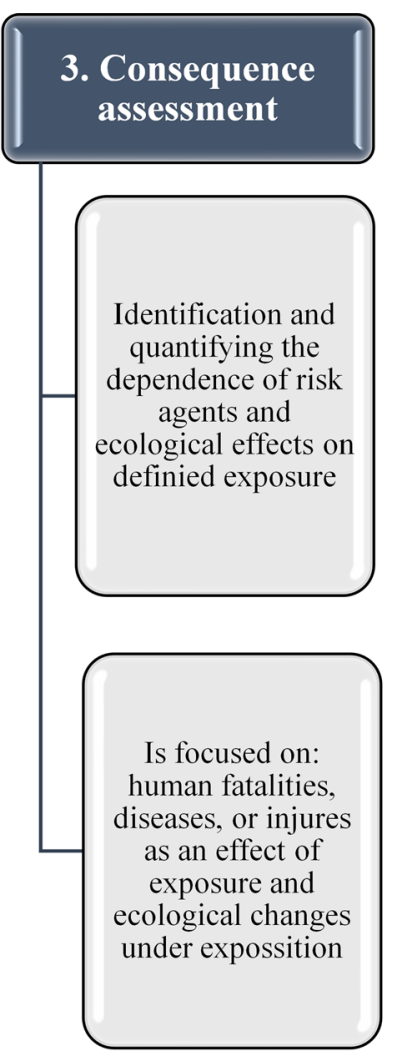

Fig. 2 A model of complete risk assessment consists of 4 stages (Covello and Merkhofer, 1993) 
information for risk management. In summary, RA is a tool to estimate the risk for humans and ecology threatened by chemicals and contaminants introduced into the environment. An effect of risk assessment is a measure or estimate of absolute values of exposure (Tsang et al. 2017; Linkov et al. 2017). The analysis may be considered in variety points of view and with different scale of details undertaken and may be taken into account as quantitative, semi-qualitative as well as qualitative. Quantitative risk provides cost/benefit assessment that may be key in decision making. On the other hand, quantitative risk requires large amount of date for different components of system, which may be problematic. In turn, in qualitative risk the quantification of threat frequency is not needed, and effort connected with it is limited. Qualitative risk is not based on the cost/benefit analysis of risk exclusion (Si et al. 2012).

The classification of the potential risk depending on the considered scenario and objective of the consideration (Liwång et al. 2013). The consequences and probability of occurring each risk in product/project needs to be assessed separately. RA is frequently used in assessing the consequences that are depended on dose of given substance/ compound. The analysis may be directed on the exposure dose, relationship of dose and level consequence and the risk severity depending on the probable dose. These scenarios constitute a general way to determinate human health risk connected with the toxicity (Ben et al. 2018; Hernández and Tsatsakis 2017).

Risk assessment constitutes the tool which allows to answer the question "what can go wrong with the project?", and hence, it should be considered as one of the most important stages in project planning. Risk assessment initially has been used mainly toward regulatory, such as establishing a new political acts or standards. Increased social interest on the field of ecology and public health forced RA direction at more wide range, including among others controlling hazardous wastes. RA considerations may involve either human health or ecological risk, and both of them may be considered separately (Manuele 2016; Topping et al. 2020).

Advantages flow from the implementation of RA in project planning included among others

- forcing the research teams and companies to implement a complex consideration of the product/project taking into account potential risk associated with the implementation of project/product;

- the need to control the risk level and monitoring its changes;
- the need to pay attention to the possibility of reducing environmental risk connected with considered product/ project;

- the need to prepare an effective and readiness emergency response means and procedure in case of the increasing environmental risk (Rausand 2011).

Risk assessment can be applicable in variety branches of industry. The most recent papers indicate their usability for human health risk evaluation of organic pigment used in the automotive industry (Pizzol et al. 2019), for human exposure to Ra-226 in oil produced water (Torres et al. 2018), in forestry decision analysis (Kangas and Kangas 2004), widely produced manufactured nanomaterials (Hristozov et al. 2016; Scott-Fordsmand et al. 2017), toxic metals in groundwaters in the aspect of human safety (Batayneh 2011) and many others.

\section{Life cycle assessment}

Life cycle assessment constitutes an opposites and contrasts to risk assessment. LCA classifies the potential impact in few categories and estimates the product influence on the environment "from cradle to grave." Due to the differences in the characteristics of those two methods, many researchers recommend the application of integrated analysis of environmental risk using both: RA and LCA methodologies (Linkov et al. 2017). In products or systems assessment using the life cycle assessment, many environmental issues and sometimes the social aspects are also taken into account. LCA provides quantitative answers regarding the environmental impact, e.g., in $\mathrm{kg}$ of $\mathrm{CO}_{2}$ equivalents for climate change. LCA is a holistic approach for considering a broad range of environmental impact throughout the entire value chain. That is one of the biggest advantages of this tool, because it allows to assess all systems that may consist of many complicated stages and processes with different environmental impacts. Moreover, LCA provides information on whether any system or product is better for the environment in terms of its environmental impact (Bjørn et al. 2018). This tool may also be useful for identification of environmental "hot points" in order to improve the quality and ecology of the production (McClelland et al. 2018).

LCA is strictly regulated by the standards of ISO (ISO 2006a, b) which distinguishes four stages:

- the goal and scope definition phase;

- LCI-life cycle inventory analysis phase;

- LCIA-life cycle impact assessment phase; 


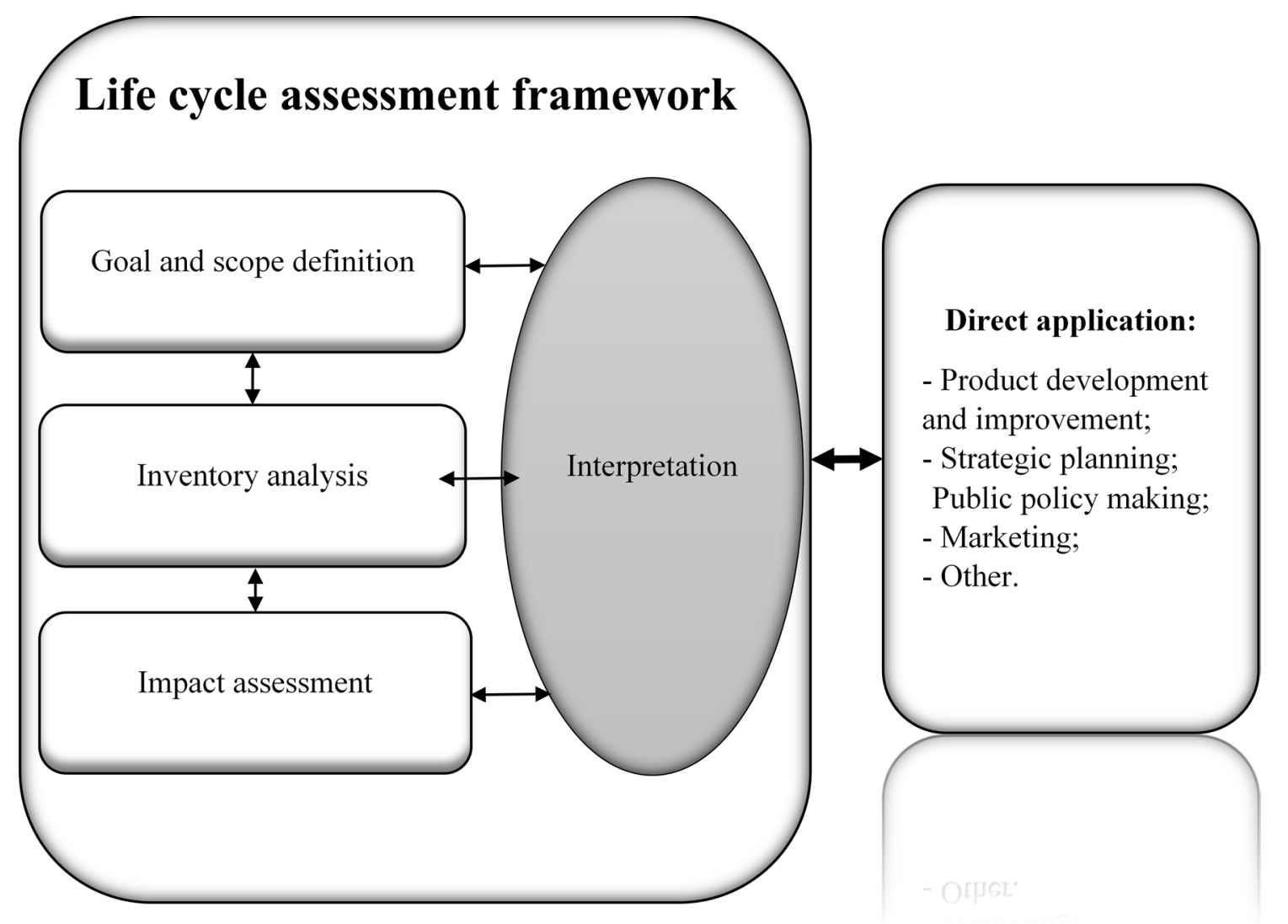

Fig. 3 Phases of an LCA (ISO 2006a)

- interpretation phase.

The last phase should contain a result of LCI and/or LCIA and provide a basis for conclusion as well as help in decision making. In LCA study, the determination of the impact categories, categories indicators and models are needed. Moreover, the choice of those elements has to be correlated with the goal of study. Phases of the LCA are shown in Fig. 3.

LCA is increasingly used in many branches of industry, and the flagship example of LCA use is environmental impact of livestock industry, for example, chicken, cattle and others (McClelland et al. 2018; de Vries and de Boer 2010; Roy et al. 2009).

\section{Life cycle inventory (LCI)}

Life cycle inventory (LCI) regards the compilation and quantification of inputs for a given product or system of products in its entire life cycle (Suh and Huppes 2005). Actually, LCI may be based on process flow diagram or IOA or matrix inversion. In principle, inventory refers to the accounting for all of the material and energy inputs and outputs throughout the life cycle of product or its whole system. In this stage, life cycle is divided into few stages. At each of them, all inputs and outputs are collected and then summarized. In life cycle inventory, all system steps are taken into account-for instance, materials, energy balance, etc. LCI describes all the relevant material and energy flows (White et al. 1995). ISO 14040: 2006a, b strictly regulates the data collection and calculation for LCA and indicates the requirements for calculation of energy flows.

\section{Life cycle impact assessment (LCIA)}

Life cycle impact assessment consist of a third stage of LCA preceding the interpretation stage. The main goal of this phase is to translate the elementary flows of the LCI into their potential contributions to the environmental impacts. LCIA consists of five stages: selection, classification, characterization, normalization, weighting. All of them are described in Fig. 4. 


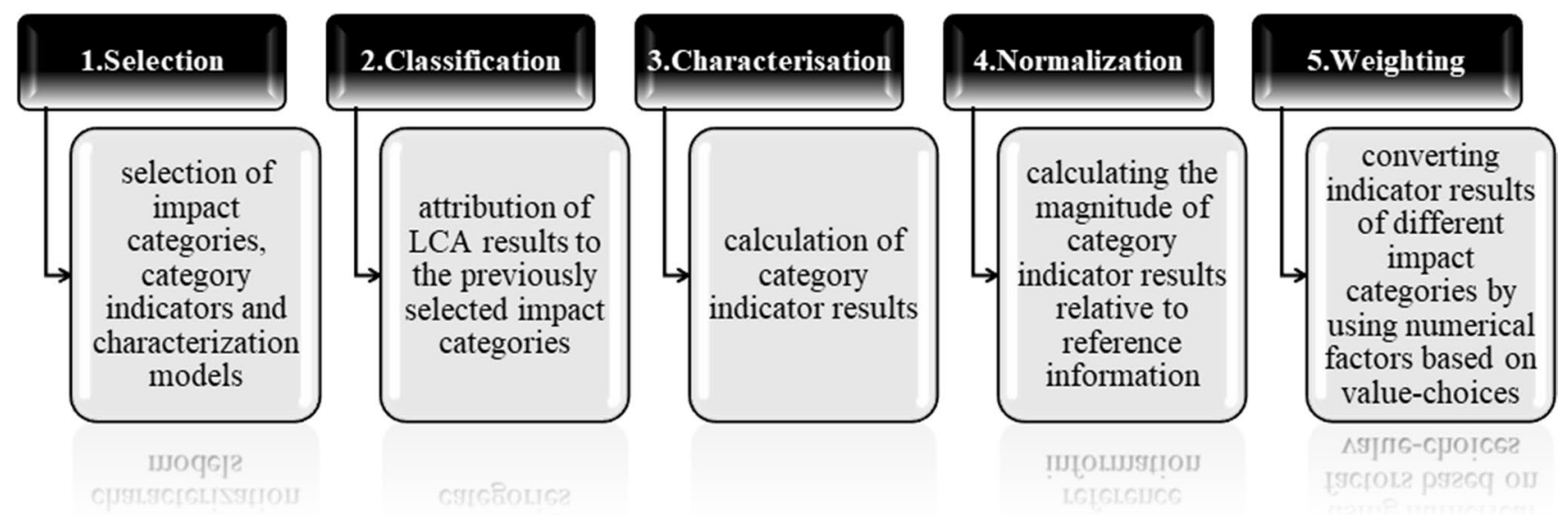

Fig. 4 Five steps of life cycle impact assessment; according to the ISO 14040:2006(E) norm (ISO ISO 2006a, b) two steps 4 and 5 are optional

Fig. 5 Impact categories in life cycle impact assessment
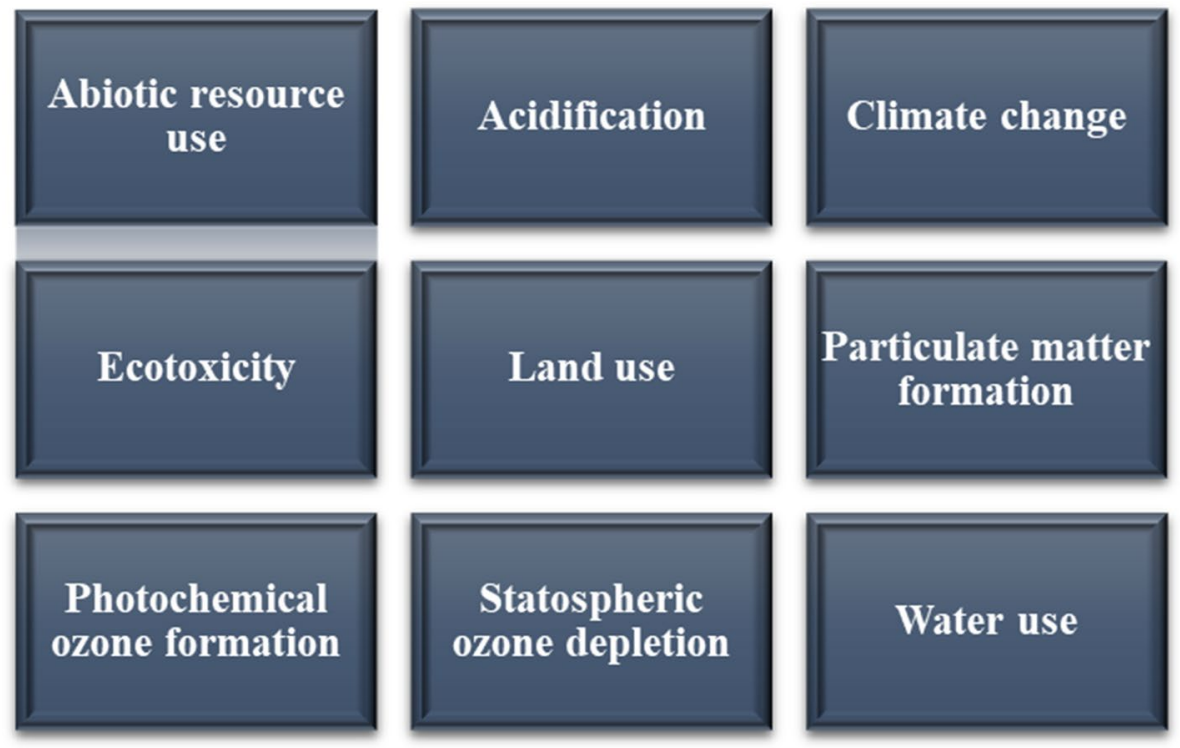

LCIA allows assigning of elementary flow to an impact category which is shown in Fig. 5.

The indicator scores achieved in characterization phases comprise a metric that differs between the selected impact categories. To achieve relative magnitudes, normalization is necessary. An effect of fourth step of LCIA achieves the data for all influence categories on a common scale. Moreover, the normalization may be useful for weighting of the indicator results. In turn, the last step allows to aggregate results across the impact categories to a single score. It may mainly contributes to facilitate interpretation (Rosenbaum et al. 2017; Rosenbaum 2017).
The interpretation and reporting constitute the final step of analysis and have to provide understandable as well as complete information.

\section{LCA software}

The following software tools are available for LCA: SimaPro (Pre Sustainability), GaBi (thikstep), Umberto (Ifu Hamburg), openLCA (GreenDelta), eBalance (IKE Environment Technology), EIME (Bureau Veritas CODDE), Quantis Suite (Quantis) Team 5 (PwC) and REGIS (sinu). 
Among them, the leading software tools for LCA are: SimaPro and GaBi (Herrmann and Moltesen 2015). SimaPro has 25-year experience in industrial and academic environment. This software provides scientific information, ensures clarity of results and avoids a black-box processes.

SimaPro might be usable in many fields, such as sustainability reporting or footprinting (C, water). Moreover, SimaPro may be a basis for environmental product declarations. This software uses many databases:

- IDEA Japanese Inventory database;

- ESU world LCA food database;

- Industry data library: PlasticsEurope, ERASM, World Steel;

- US LifeCycle Inventory database;

- Social hotspots database;

- Ecoinvent;

- Swiss Input/Output database;

- DATASMART LCI package;

- AGRIBALYSE;

- Agri-footprint;

- ELCD;

- European and Danish Input/Output database

In turn, $\mathrm{GaBi}$ provides four databases:
Both of these software tools are applicable for circular economy, life cycle assessment, building LCA, certification of buildings, sustainable design, ErP directive and ecodesign, environmental product declarations, green IT, product carbon footprint, ecological footprint, product environmental footprint, resource and energy efficiency and water footprint. $\mathrm{GaBi}$ allows determining the strategic risks and environmental optimization opportunities of a product at its early stages. Each of the stages in life cycle of the product may be determined in magnitude and importance.

Herrmann and Moltesen (2015) compared these two software tools and noticed the differences in LCA results between them. Those differences may be effects of different errors and databases used in both tools. Particularly, the high differences were observed in modeling of aquatic eutrophication using EDIP 2003 as shown in Fig. 6.

Similarly to RA, LCA has a wide application in many branches of industry such as food industry (Nikolaou et al. 2019), architecture industry (Szamosi et al. 2020), chemical industry (Santos et al. 2019), textile industry (Balanay and Halog 2019), minerals industry (Segura-Salazar et al. 2019) and many others.

- GaBi databases,

- ecoinvent,

- U.S. LCI,

- Data on demand.

Fig. 6 Illustration of possible differences between modeling aquatic eutrophication using EDIP 2003 with two LCA tools: SimaPro $(\mathrm{S})$ and $\mathrm{GaBi}(\mathrm{G})$ in the biodiesel case. S-PWB1-8 are modeled with SimaPro, and G-PWB1-8 are the result when multiplied by a factor of 6.3 as found in the SBF Sect. 4.2.1 EDIP 2003 results above (Herrmann and Moltesen 2015)

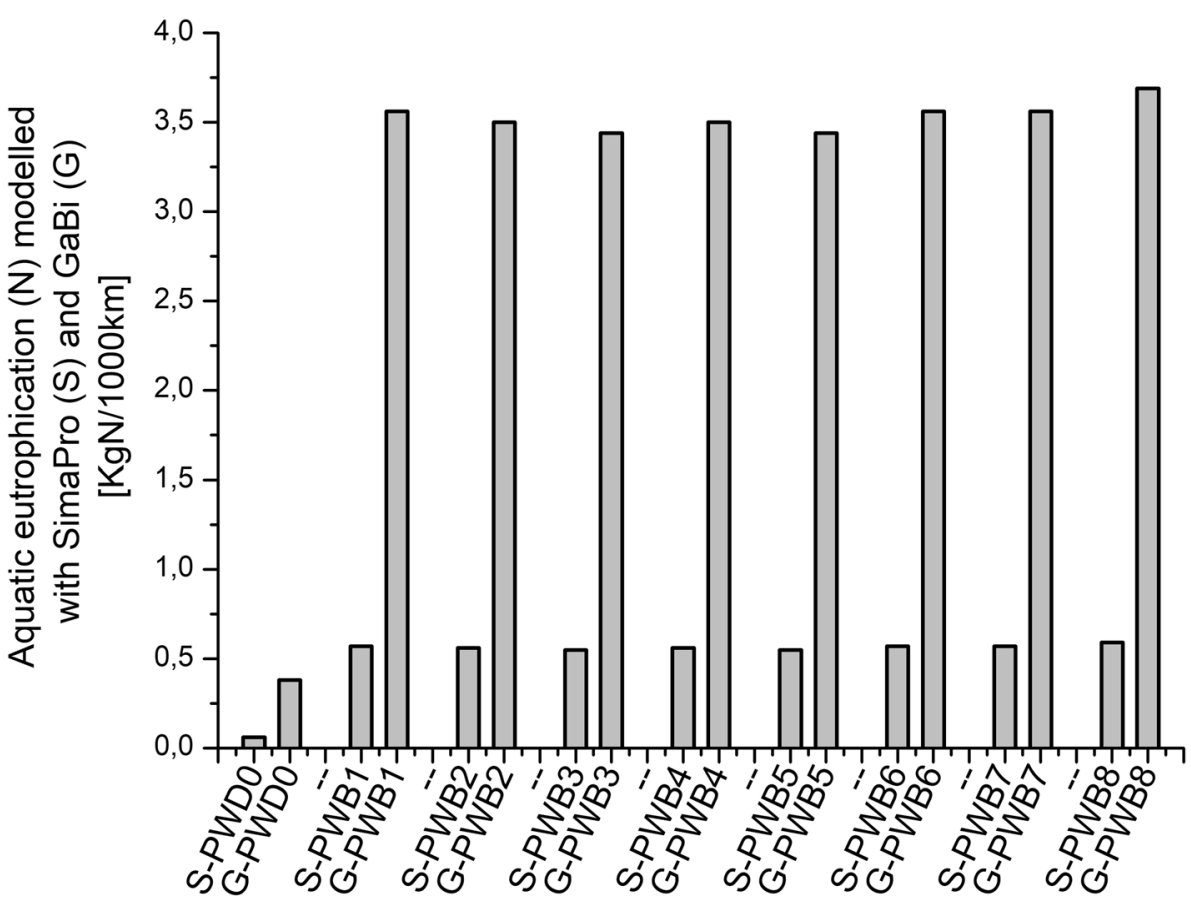


Table 1 Comparison of environmental RA (based on Linkov et al. 2017; Breedveld 2013)

\begin{tabular}{|c|c|c|}
\hline & Risk assessment & Life cycle assessment \\
\hline Rule & Above threshold values & Less is better \\
\hline Aim & $\begin{array}{l}\text { Environmental risk estimation; to check if risk management is } \\
\text { necessary to not exceed threshold values; }\end{array}$ & $\begin{array}{l}\text { Assessment of potential impacts; to check environmental } \\
\text { risk for all stages of life and indicate the stage of the most } \\
\text { exposing environment; }\end{array}$ \\
\hline Scope & Substances released to the environment & Life cycle perspective \\
\hline Approach & Initial risk assessment consists of the worst case & Realistic comparison for product comparison \\
\hline Dimension & Concentration and dose & Number of emission \\
\hline Reference & Threshold values & Characterization factor \\
\hline Achieved results & $\begin{array}{l}\text { Shown as chemical exposure compared to threshold values } \\
\text { for environmental impact }\end{array}$ & Shown as estimated potential impact \\
\hline Spatial level & Local or regional level & Global to regional level \\
\hline
\end{tabular}

\section{Fundamental differences and similarities between RA and LCA}

While both analytical tools have their own supporters and opponents, ranking all pros and cons is necessary to decide which of them will be more suitable for the specific research. Many studies regarding environmental risk assessment and life cycle assessment suggested that those methodologies may have a supplemental role in estimation of risk, despite having slightly different goals (Barberio et al. 2014; de Haes et al. 2006; Bare 2006). The combination of ERA and LCA may provide complete and scientifically significant data for detailed evaluation of the influence on the environment and human health (Barberio et al. 2014). The main divergence in those tools is how the tool deals with the analysis. In risk assessment, all data above the threshold values are considered, while in life cycle assessment according to the rule "less is better," the attention is paid to the prevention of concentration levels resulting from many different (usually far away) sources. It may be a mixture of various substances that, alone or together, may pose a huge environmental threat (Breedveld 2013). Moreover, LCA allows estimating only the potential impacts due to the exclusion of time and space dimensions, while by risk assessment it is possible to determinate the actual environmental risk (Guinée and Heijungs 1993). In LCA, the most important unit is the functional unit (FU) for which all environmental impact is calculated. In turn, environmental risk assessment shows risk for actual emission volumes. Therefore, in risk assessment the worst values may be used in the assessment for initial the RA purposes. Unlike RA, LCA consists of indirect product systems, and in comparing two systems or products the use of the worst-case values is not necessary and is highly debatable (Breedveld 2013).

The comparison of both methods will be better noticeable for specific case-for instance:

Case 1: introduction of sewage sludge into soil highly polluted with heavy metals;

Case 2: introduction of sewage sludge into soil not polluted with heavy metals

According to LCA and RA, the LCA will probably determine a minimal soil remediation effect (by immobilization of heavy metals) and minimal emissions in Case 1 due to the significance of treatment process and required transport. By contrast, RA will state the minimal environmental risk due to the concentration of the main process within the life cycle (transport and treatments are not considered additionally in comparison with LCA). In Case 1, in LCA it particularly needs to provide an information about starting status of soil contamination with heavy metals (HMs), HMs' content in sewage sludge that is considered to soil application, as well as overall heavy metals' fate in remediation process that contribute to the environmental effect. Using LCA methodology in comparison between a few considered sewage sludges, the LCA software will indicate this one which shows the lowest environmental impact. In comparison with the LCA, RA in such case will indicate those ones which will be above or below fixed threshold value. Thus, LCA will indicate an environmental impact of all selected scenarios with considered sewage sludge; in turn, RA will indicate how their use influences meeting requirements according to fixed threshold values. Thus, the interpretation of the feedback from these tools is slightly different and requires focus from conducting 
the analysis. In study comparing Case 1 and Case 2, LCA method will show the difference in environmental impact of sewage sludge application into a soil addicted to the contamination level. The LCA will show how application of biowaste affects the heavy metal contamination and indicate if environmental impact of heavy metals in the soil will increase with sewage sludge application. In turn, RA will only refer to the threshold values (in such cases, particularly heavy metals concentration) and refer it to both cases. Therefore, in such cases, LCA will show the overall emission connected with increased/decreased HMs contamination and application of sewage sludge, while RA will refer to the HMs concentration and its toxic exposure.

The similarities between both tools have been discussed by many researchers (Xue et al. 2019; Linkov et al. 2017; Pant et al. 2004; Breedveld 2013). Breedveld (2013) showed the possibility to combine both tools which can provide widespread results and contribute to more detailed results shown in Table 1. Among advantages driven by combined use of those tools, RA may provide detailed scientific models for LCA, and on the other hand, LCA may complement RA. Hence, those tools may be applied in different ways: separately, as a subset for RA or LCA, and together as well (Breedveld 2013). Basing on the opportunities of RA, life cycle-based risk assessment (LCBRA) was created, which allows determining risks along life cycle stages for a given product system. In such tool, RA forms a strong basis for assessment, but analysis is conducted for all life cycle. Integrated LCA and RA seem to be particularly relevant to assist decision making in future sustainability assessments (Breedveld 2013).

\section{Conclusion}

Risk assessment and life cycle assessment constitute the most frequently used method directed on environmental and human health risk assessment. Their use requires a precise collection of data for characterization, normalization and weighting whose analysis allows for estimation of environmental risk and may be key in decision making in mitigation and limitation of environmental risk connected with considered scenario. For evaluation of an environmental impact, the LCA seems to be the most precise tool and allows achieving risk's likelihood in few categories. The application of risk evaluation of the implemented process or product contributes to the sustainable development and promotes a pro-ecological approach. Proceeding of those assessments consists of a precious equivalent for decision making and may serve as an indicator for usability of new technologies. Nevertheless, the results achieved via LCA software have to be carefully interpreted. Even if LCA and RA have been created for different objectives, their hybrid is recommended as it can provide a relevant and different assessment perspectives allowing for completely new and valuable support in decision making.

Acknowledgement The research leading to these results has received funding from the EnviSafeBioC project-contract No PPI/ APM/2018/1/00029/U/001. The project is financed by the Polish National Agency for Academic Exchange (NAWA).

Open Access This article is licensed under a Creative Commons Attribution 4.0 International License, which permits use, sharing, adaptation, distribution and reproduction in any medium or format, as long as you give appropriate credit to the original author(s) and the source, provide a link to the Creative Commons licence, and indicate if changes were made. The images or other third party material in this article are included in the article's Creative Commons licence, unless indicated otherwise in a credit line to the material. If material is not included in the article's Creative Commons licence and your intended use is not permitted by statutory regulation or exceeds the permitted use, you will need to obtain permission directly from the copyright holder. To view a copy of this licence, visit http://creativecommons.org/licenses/by/4.0/.

\section{References}

Althor G, Watson JEM, Fuller RA (2016) Global mismatch between greenhouse gas emissions and the burden of climate change. Sci Rep 6:1-6. https://doi.org/10.1038/srep20281

Balanay R, Halog A (2019) Tools for circular economy review and some potential applications for the Philippine textile industry. Circ Econ Text Apparel. https://doi.org/10.1016/b978-0-08-10263 0-4.00003-0

Barberio G, Scalbi S, Buttol P, Masoni P, Righi S (2014) Combining life cycle assessment and qualitative risk assessment: the case study of alumina nanofluid production. Sci Tot Environ 496:122131. https://doi.org/10.1016/j.scitotenv.2014.06.135

Bare JC (2006) Risk assessment and life-cycle impact assessment (LCIA) for human health cancerous and noncancerous emissions: integrated and complementary with consistency within the USEPA. Hum Ecol Risk Assess 12:493-509. https://doi. org/10.1080/10807030600561683

Batayneh AT (2011) Toxic (aluminum, beryllium, boron, chromium and zinc) in groundwater: health risk assessment. Int J Environ Sci Technol 9(1):153-162. https://doi.org/10.1007/s1376 2-011-0009-3

Beer T (1995) Ziółkowski F (1995) Environmental risk assessment: an Australian perspective. EPA, Australia

Ben Y, Fu C, Hu M, Liu L, Wong MH, Zheng C (2018) Human health risk assessment of antibiotic resistance associated with antibiotic residues in the environment: a review. Environ Res 169:483-493. https://doi.org/10.1016/j.envres.2018.11.040

Bjørn A, Owsianiak M, Mollin C, Laurent A (2018) Main characteristics of LCA. In: Hauschuld MZ, Rosenbaum RK, Olsen SI (eds) Life cycle assessment. Theory and practice. Springer, Berlin, pp 9-16 
Breedveld L (2013) Combining LCA and RA for the integrated risk management of emerging technologies. J Risk Res 16(3-4):459_ 468. https://doi.org/10.1080/13669877.2012.729526

Chen H, Teng Y, Lu S, Wang Y, Wang J (2015) Contamination features and health risk of soil heavy metals in China. Sci Total Environ 512-513:143-153. https://doi.org/10.1016/j.scitotenv.2015.01.025

Covello VT, Merkhofer MW (1993) Introduction to Risk Assessment. In: Risk assessment methods. Springer, Boston, MA

De Haes U, Sleeswijk AW, Heijungs R (2006) Similarities, difference and synergisms between HERA and LCA - an analysis at three levels. Hum Ecol Risk Assess 12(3):431-449. https://doi. org/10.1080/10807030600561659

de Vries M, de Boer IJM (2010) Comparing environmental impacts for live- stock products: a review of life cycle assessments. Livest Sci 128:1-11. https://doi.org/10.1016/j.livsci.2009.11.007

Denmark OF (2011) Environmental impacts on the genome and epigenome: mechanisms and risks. Environ Mol Mutagen 52(1):13-87

Finnveden G, Hauschild MZ, Ekvall T, Guinée J, Heijungs R, Hellweg S, Suh S (2009) Recent developments in Life Cycle Assessment. J Environ Manag 91(1):1-21. https://doi.org/10.1016/j.jenvm an.2009.06.018

Grobelak A, Placek A, Grosser A, Singh BR, Almås ÅR, Napora A, Kacprzak M (2017) Effects of single sewage sludge application on soil phytoremediation. J Clean Prod 155:189-197. https://doi. org/10.1016/j.jclepro.2016.10.005

Guinée J, Heijungs R (1993) A proposal for the classification of toxic substances within the framework of life cycle assessment of products. Chemosphere 26(10):1925-1944. https://doi. org/10.1016/0045-6535(93)90086-K

Harder AT, Knorth EJ, Kalverboer ME (2015a) Risky or needy? Dynamic risk factors and delinquent behavior of adolescents in secure residential youth care. Int J Offender Ther Comp Criminol 59(10):1047-1065. https://doi.org/10.1177/0306624X14531036

Harder R, Holmquist H, Molander S, Svanström M, Peters GM (2015b) Review of environmental assessment case studies blending elements of risk assessment and life cycle assessment. Environ Sci Technol 49(22):13083-13093. https://doi.org/10.1021/acs. est.5b03302

Hernández AF, Tsatsakis AM (2017) Human exposure to chemical mixtures: challenges for the integration of toxicology with epidemiology data in risk assessment. Food Chem Toxicol 103:188193. https://doi.org/10.1016/j.fct.2017.03.012

Herrmann IT, Moltesen A (2015) Does it matter which Life Cycle Assessment (LCA) tool you choose? - a comparative assessment of SimaPro and GaBi. J Clean Prod 86:163-169. https://doi. org/10.1016/j.jclepro.2014.08.004

Hristozov D, Gottardo S, Semenzin E, Oomen A, Bos P, Peijnenburg W, Marcomini A (2016) Frameworks and tools for risk assessment of manufactured nanomaterials. Environ Internat 95:36-53. https ://doi.org/10.1016/j.envint.2016.07.016

ISO (2006a) ISO 14040. Environmental management-life cycle assessment-principles and framework. International Organization for Standardization, Geneva, p 20

ISO (2006b) ISO 14044. Environmental management-life cycle assessment-requirements and guidelines. International Organization for Standardization, Geneva, $\mathrm{p} 46$

Jasch C (2000) Environmental performance evaluation and indicators. J Clean Prod 8(1):79-88. https://doi.org/10.1016/S0959 $-6526(99) 00235-8$

Kangas AS, Kangas J (2004) Probability, possibility and evidence: approaches to consider risk and uncertainty in forestry decision analysis. For Policy Econ 6(2):169-188. https://doi.org/10.1016/ s1389-9341(02)00083-7

Kowalska A, Grobelak A (2020) Chapter 14-Organic matter decomposition under warming climatic conditions. In: Prasad MNV, Pietrzykowski M (eds) Climate change and soil interactions, pp 397-412. https://doi.org/10.1016/B978-0-12-818032-7.00014-X

Linkov I, Trump BD, Wender BA, Seager TP, Kennedy AJ, Keisler JM (2017) Integrate life-cycle assessment and risk analysis results, not methods. Nat Nanotechnol 12(8):740-743. https:// doi.org/10.1038/nnano.2017.152

Liwång H, Ringsberg JW, Norsell M (2013) Quantitative risk analysis-ship security analysis for effective risk control options. Saf Sci 58:98-112. https://doi.org/10.1016/j.ssci.2013.04.003

Manuele FA (2016) Chapter 1: Risk assessments: their significance and the role of the safety professional. In: Popov G, Lyon BK, Hollcraft B (eds) Risk assessment: a practical guide to assessing operational risks. Wiley, Hoboken, pp 1-22.

Mardones C, Bienzobas R (2019) Ex-post evaluation of clean production agreements in the Chilean industrial sectors. J Clean Prod 213:808-818. https://doi.org/10.1016/j.jclepro.2018.12.228

Matuszak-Flejszman A, Szyszka B, Jóhannsdóttir L (2019) Effectiveness of EMAS: a case study of Polish organisations registered under EMAS. Environ Impact Assess Rev 74:86-94. https://doi. org/10.1016/j.eiar.2018.09.005

McClelland SC, Arndt C, Gordon DR, Thoma G (2018) Type and number of environmental impact categories used in livestock life cycle assessment: a systematic review. Livest Sci 209:39-45. https ://doi.org/10.1016/j.livsci.2018.01.008

Montobbio F, Solito I (2018) Does the Eco-Management and Audit Scheme Foster Innovation in European Firms? Bus Strat Env 27(1):82-99. https://doi.org/10.1002/bse.1986

Nan A, Filip X, Dan M, Marincaş O (2019) Clean production of new functional coatings of magnetic nanoparticles from sustainable resources. J Clean Prod 210:687-696. https://doi.org/10.1016/j. jclepro.2018.11.069

Nikolaou IE, Tsalis T, Evangelinos K (2019) A LCA technique to measure the socially business responsible profile: the case of food industry. In: Muthu SS (ed) Social life cycle assessment: case studies from agri and food sectors, pp 39-57. https://doi. org/10.1007/978-981-13-3236-4_2

Pant R, Van Hoof G, Schowanek D, Feijtel TCJ, de Koning A, Hauschild M, Pennington DW, Olsen SI, Rosenbaum R (2004) Comparison between three different LCIA methods for aquatic ecotoxicity and a product environmental risk assessment. Int J Life Cycle Assess 9(5):295-306. https://doi.org/10.1065/ica2004.08.165

Pizzol L, Hristozov D, Zabeo A, Basei G, Wohlleben W, Koivisto AJ et al (2019) SUNDS probabilistic human health riskassessment methodology and its application to organic pigment used in the automotive industry. NanoImpact 13:26-36. https://doi. org/10.1016/j.impact.2018.12.001

Rausand M (2011) Risk assessment: theory, methods, and applications. Wiley, Hoboken

Rosenbaum RK (2017) Ecotoxicity. In: Hauschild MZ, Rosenbaum RK, Olsen SI (eds) Life cycle assessment: theory and practice. Springer, Cham, pp 425-428

Rosenbaum RK, Hauschild MZ, Boulay AM, Fantke P, Laurent A, Núñez M, Vieira M (2017) Life cycle impact assessment. In: Hauschild MZ, Rosenbaum RK, Olsen SI (ed) Life cycle assessment: theory and practice. https://doi.org/10.1007/978-3-31956475-3_10

Roy P, Nei D, Orikasa T, Xu Q, Okadome H, Nakamura N, Shiina T (2009) A review of life cycle assessment (LCA) on some food 
products. J Food Eng 90:1-10. https://doi.org/10.1016/j.jfood eng.2008.06.016

Różański SŁ, Kwasowski W, Castejón JMP, Hardy A (2018) Heavy metal content and mobility in urban soils of public playgrounds and sport facility areas, Poland. Chemosphere 212:456-466. https ://doi.org/10.1016/j.chemosphere.2018.08.109

Santos A, Barbosa-Póvoa A, Carvalho A (2019) Life cycle assessment in chemical industry-a review. Curr Opin Chem Eng 26:139147. https://doi.org/10.1016/j.coche.2019.09.009

Schwarz K, Pouyat RV, Yesilonis I (2016) Legacies of lead in charm city's soil: lessons from the baltimore ecosystem study. Int J Environ Res Public Health 13(2):209-222. https://doi.org/10.3390/ ijerph13020209

Scott-Fordsmand JJ, Peijnenburg WJGM, Semenzin E, Nowack B, Hunt N, Hristozov D, Hund-Rinke K (2017) Environmental risk assessment strategy for nanomaterials. Int J Environ Res Public Health 14(10):1251-2171. https://doi.org/10.3390/ijerph1410 1251

Segura-Salazar J, Lima FM, Tavares LM (2019) Life Cycle Assessment in the minerals industry: current practice, harmonization efforts, and potential improvement through the integration with process simulation. J Clean Prod 232:174-192. https://doi.org/10.1016/j. jclepro.2019.05.318

Si H, Ji H, Zeng X (2012) Quantitative risk assessment model of hazardous chemicals leakage and application. Saf Sci 50(7):14521461. https://doi.org/10.1016/j.ssci.2012.01.011

Suh S, Huppes G (2005) Methods for life cycle inventory of a product. J Clean Prod 13(7):687-697. https://doi.org/10.1016/j.jclep ro.2003.04.001

Suo C, Li YP, Jin SW, Liu J, Li YF, Feng RF (2017) Identifying optimal clean-production pattern for energy systems under uncertainty through introducing carbon emission trading and green certificate schemes. J Clean Prod 161:299-316. https://doi.org/10.1016/j. jclepro.2017.05.123

Suter GW (2006) Ecological risk assessment. Taylor \& Francis, Boca Raton

Szamosi Z, Bodnár I, Szepesi GL, Rosas-Casals M, Berényi L (2020) Improved environmental impact in the architecture industry:
LCA analysis of an alternative masonry element. Renew Energy 147:1718-1727. https://doi.org/10.1016/j.renene.2019.09.118

Topping CJ, Aldrich A, Berny P (2020) Overhaul environmental risk assessment for pesticides. Science 367:360-363. https://doi. org/10.1126/science.aay 1144

Torres L, Yadav OP, Khan E (2018) Risk assessment of human exposure to Ra-226 in oil produced water from the Bakken Shale. Sci Total Environ 626:867-874. https://doi.org/10.1016/j.scito tenv.2018.01.171

Toruński (2010) Environmental aspects of sustainable development of legally protected areas 9in Polish. Zeszyty Naukowe Akademii Podlaskiej in Siedlce, series: Administration and Management 84:21-32

Tsang MP, Kikuchi-Uehara E, Sonnemann GW, Aymonier C, Hirao M (2017) Evaluating nanotechnology opportunities and risks through integration of life-cycle and risk assessment. Nat Natochenol 12(8):734-739. https://doi.org/10.1038/nnano.2017.132

Urban MC (2015) Accelerating exctinction risk from climate change. Science 384:571-573. https://doi.org/10.1126/science.aaa4984

US Environmental Protection Agency (1998) Guidelines for ecological risk assessment. Washington

White P, Franke M, Hindle P (1995) Integrated solid waste management: a lifecycle inventory. Blackie Academic \& Professional, London

Wójcik M (2018) Kompleksowa analiza ryzyka środowiskowego dla procesów poszukiwania i eksploatacji niekonwencjonalnych złóż węglowodorów typu shale gas w Polsce. Nafta-Gaz 74(3):208214. https://doi.org/10.18668/ng.2018.03.04

Xue M, Kojima N, Zhou L, Machimura T, Tokai A (2019) Trade-off analysis between global impact potential and local risk: a case study of refrigerants. J Clean Prod 217:627-632. https://doi. org/10.1016/j.jclepro.2019.01.293

Yoshida H, ten Hoeve M, Christensen TH, Bruun S, Jensen LS, Scheutz C (2018) Life cycle assessment of sewage sludge management options including long-term impacts after land application. J Clean Prod 174:538-547. https://doi.org/10.1016/j.jclep ro.2017.10.175 